\title{
Disentangling the effects of dispersal mode on the assembly of macroinvertebrate assemblages in a heterogeneous highland region
}

\author{
Zhengfei $\mathrm{Li}^{1,3,4}$, Jun Wang ${ }^{1,3,5}$, Xingliang Meng ${ }^{1,6}$, Jani Heino ${ }^{2,7}$, Meiqin Sun ${ }^{1,8}$, Xiaoming Jiang ${ }^{1,9}$, \\ and Zhicai Xie ${ }^{1,10}$ \\ ${ }^{1}$ The Key Laboratory of Aquatic Biodiversity and Conservation, Institute of Hydrobiology, Chinese Academy of Sciences, \\ Wuhan 430072, China \\ ${ }^{2}$ Biodiversity Centre, Finnish Environment Institute, Paavo Havaksen Tie 3, P.O. Box 413, 90014 Oulu, Finland \\ ${ }^{3}$ University of Chinese Academy of Sciences, Beijing 100049, China
}

\begin{abstract}
Disentangling the effects of dispersal mode on the environmental and spatial processes structuring biological assemblages is essential to understanding the mechanisms of species coexistence and maintenance. Here, we use field investigations to link dispersal mode with environmental and spatial processes that control stream macroinvertebrate assemblage structure across the Yarlung Zangbo Grand Canyon of Tibet (Tibetan Plateau). We sampled macroinvertebrates in streams that occur in 4 distinct regions. Each of these regions has a steep elevational gradient but different altitude ranges, climate types, and water replenishment sources. We classified macroinvertebrate taxa into passive and active dispersal mode groups to test whether macroinvertebrates with different dispersal modes responded differently to environmental and spatial processes. Our results showed that the assemblage structure of active dispersal groups was more strongly determined by environmental variables (habitat filtering/species sorting) than spatial factors both within and across regions. In contrast, the structure of passive dispersers was more strongly associated with spatial factors than environmental filtering in the entire study area and within lower canyon regions. However, spatial effects were not important for either type of dispersal group in the upper canyon regions, especially in the region with glacier-fed streams, indicating the predominance of species sorting processes in these harsh environments. Furthermore, the spatial structuring of assemblages became stronger as habitat filtering declined, which indicates a reduction in species sorting processes in less harsh environments. Our findings demonstrate diverse responses of macroinvertebrate assemblages to environmental and spatial processes across this poorly-known highland river system, and imply that dispersal mode influences the underlying mechanisms of community variation.
\end{abstract}

Key words: Tibetan streams, dispersal mode, elevational gradient, glacial streams, spatial effects, environmental filtering

Understanding the processes and mechanisms of species coexistence and maintenance in local communities at different spatial scales has long been a critical task of ecologists (Wright 2002). Over the past few decades, many ecological theories and hypotheses concerning community assembly and species coexistence have been proposed (Leibold and Chase 2017). Of these, niche theory emphasizes the significance of environmental filtering by local abiotic factors and biotic interactions (Leibold et al. 2004, Urban 2004, Zhao et al. 2017), such as ecosystem physiochemistry, disturbance regime, productivity, and interspecific competition (Hirzel and Le Lay 2008, Heino et al. 2015b). In contrast, neutral theory explicitly ignores the differences in how taxa in a community respond to local ecological conditions, and instead highlights the importance of random processes (e.g., dispersal and ecological drift) in structuring local commu-

E-mail addresses: ${ }^{4}$ lizhengfei@ihb.ac.cn; ${ }^{5}$ wangjun@ihb.ac.cn; ${ }^{6}$ xingliang01@ihb.ac.cn; ${ }^{7}$ jani.heino@ymparisto.fi; ${ }^{8}$ sunmeiqin@ihb.ac.cn; To whom correspondence should be addressed: ${ }^{9}$ jiangxm@ihb.ac.cn; ${ }^{10}$ zhcxie@ihb.ac.cn 
nities (Hubbell 2001, Thompson and Townsend 2006). In recent decades, it has been increasingly recognized that local community structure is determined by both deterministic (e.g., environmental filtering) and stochastic (e.g., dispersal, drift) processes. However, the relative importance of deterministic and stochastic processes can vary among organism groups and spatio-temporal scales (Qian and Ricklefs 2007, Qian et al. 2009, Logue et al. 2011, Heino et al. 2012, Jiang et al. 2017).

A set of local communities linked by the dispersal of multiple species that may interact is defined as a metacommunity (Leibold et al. 2004, Cottenie 2005). Dispersal is critical to the local persistence of many species (Patrick et al. 2014). Further, environmental filtering processes can only act once individuals disperse to a new location. Barriers to dispersal, therefore, act as spatial filters before environmental filters can act (Gray and Arnott 2011, Heino 2013a, Tonkin et al. 2018). Consequently, theory predicts that the relative importance of spatial process (e.g., dispersal limitation) and environmental filtering depends on the dispersal traits of the focal organisms (Martiny et al. 2006, Patrick et al. 2014). Recently, many studies have compared taxa with different dispersal traits to determine how dispersal mode and ability influence the relative importance of spatial and environmental filtering processes in shaping metacommunity patterns (Heino et al. 2012, Landeiro et al. 2012, Heino 2013a, Zhao et al. 2017).

Stream macroinvertebrates have multiple dispersal strategies, including both active and passive dispersal via water or air, which make them an ideal group to address how dispersal mode affects metacommunity structure. Stream macroinvertebrates can use aquatic dispersal by either passively drifting and relying on external water or wind flow, attaching to animal vectors, or actively moving along the stream network. Alternatively, some stream invertebrates can use aerial dispersal, primarily by active flight or passive wind drift (Li et al. 2016, Tonkin et al. 2018). Active dispersers should show active habitat selection because they should be able to track environmental variation better than passive dispersers. Thus, active dispersers should be more strongly influenced by variation in environmental conditions than by spatial structuring (i.e., dispersal limitation). In contrast, passive dispersers should display stronger spatial structuring and weaker local environmental control, because they cannot effectively track environmental variation and may thus be absent from suitable sites (Cauvy-Fraunié et al. 2015, Hill et al. 2017).

The application of metacommunity theory has received considerable attention from stream ecologists in recent years (Tonkin et al. 2018), but the primary focus has been on community assembly mechanisms in a single region (e.g., reach, river or catchment; Heino et al. 2012). However, ecological patterns and their mechanistic basis may also differ among regions (Tonkin et al. 2016a), because different regions often have different species composition, taxonomic variability, and functional composition as a result of historical effects and climatic constraints (Heino et al. 2005). Focusing on relatively few, small-scale, or environmentally similar localities will therefore limit the generalizations stream researchers can make about metacommunity theory in stream systems. Moreover, stream communities are affected by processes operating from local to within-region and even across-region scales, so studies should also compare the effects of environmental, spatial, and regional factors on metacommunity structuring over large areas (Heino et al. 2017b). Thus, it is necessary to carry out broad investigations involving different geographic regions, elevation ranges, climate types, and habitat characteristics (Qian and Ricklefs 2007, Landeiro et al. 2012, Myers et al. 2013, Grimaldo et al. 2016). These investigations should facilitate our understanding of the mechanisms and processes that underlie species coexistence and persistence in biological communities.

The Tibetan Plateau is the largest and highest plateau in the world, and supports a uniquely diverse flora and fauna that make it one of the world's most important alpine biodiversity hotspots (Jiang et al. 2013, Tonkin et al. 2016b). This region has a large elevation range and mountain barriers that result in many geographically isolated regions that harbor diverse climate types, complex environmental characteristics, and endemic organisms (Yao et al. 2007). These unique conditions make this region ideal for exploring the patterns and processes of community assembly at withinand across-region scales. Macroinvertebrate research in $\mathrm{Ti}$ betan freshwater ecosystems has mainly focused on describing the characteristics of species composition and diversity patterns (Laursen et al. 2015) and assessing assemblageenvironment relationships (Jiang et al. 2013). No previous studies have examined the relative importance of both environmental and spatial effects in structuring metacommunities of stream macroinvertebrates, although similar investigations have been done in some regions of the Himalayas (Tonkin et al. 2016b).

Here, we examined how macroinvertebrate groups with different dispersal modes respond to environmental and spatial processes in 4 regions with different altitude ranges, climate types, and water replenishment sources across the Yarlung Zangbo Grand Canyon area of the Tibetan Plateau. Our primary aim was to test the following hypotheses: 1) environmental variables are more important than spatial factors in structuring the communities of active dispersers, whereas spatial factors are more influential in determining the communities of passive dispersers; 2) the relative importance of environmental and spatial factors in structuring assemblages varies across regions. We also compared the relative explanatory power of 2 spatial models based on straight-line and watercourse distance, and examined the possible mechanisms underlying differences in the relative importance of spatial and environmental processes in the 4 regions. 


\section{METHODS}

\section{Study area}

We conducted this study in the Yarlung Zangbo Grand Canyon Region (lat $26^{\circ} 52^{\prime}-30^{\circ} 40^{\prime} \mathrm{N}$, long $92^{\circ} 09^{\prime}-98^{\circ} 47^{\prime} \mathrm{E}$ ), in southeastern Tibet. The Grand Canyon is the deepest canyon in the world, and consists primarily of alpine canyon, valley plain, intermountain basin, and lake basin habitats (Deng et al. 2011). The region covers $117,000 \mathrm{~km}^{2}$ in total, and has complex landforms with a unique ecosystem of animals and plants species that have barely been studied, explored, or influenced by human activities (Li et al. 2014). This region is also densely covered with rivers, lakes, and other forms of water resources such as glaciers. Climate conditions in this region range from tropical to temperate and subarctic zones, and the maximum elevation gradient is about $7000 \mathrm{~m}$.

We sampled stream macroinvertebrate assemblages from 4 drainage basins (regions) along the Yarlung Tsangpo River, which flows through the Grand Canyon. These basins are distinguished by their elevation ranges, climate types, and water replenishment sources (e.g., glacier- or precipitationfed). Two of the regions are located in the upper regions of the Grand Canyon, in Linzhi City (14 sites, hereafter LZ) and Bomi County (11 sites, BM), including the Parlung Zangbo River and other tributaries of the midstream Yalutsangpo. These regions each range in altitude from $\sim 2600$ to $3600 \mathrm{~m}$ and are characterized by a humid continental climate. The streams in LZ are replenished primarily by snowmelt, with some input from precipitation and groundwater (Dawaciren and Baima 2008). In contrast, the streams in BM are replenished mainly by glacier-melt, which accounts for more than half of their annual runoff (Zhang et al. 2011, Xiang et al. 2013). The other 2 regions are located in the lower reaches of the Grand Canyon in Chayu County (13 sites, CY) and Motuo County (14 sites, MT). CY and MT both have a humid subtropical climate, are replenished primarily by rainfall, and have altitude ranges of $\sim 1400$ to $2100 \mathrm{~m}$ and $\sim 600$ to $900 \mathrm{~m}$, respectively.

\section{Macroinvertebrate sampling and taxa grouping}

In October 2015, we sampled benthic macroinvertebrates from 52 stream sites in southeastern Tibet (Fig. 1). At each site, we took 3 quantitative samples from the repre-
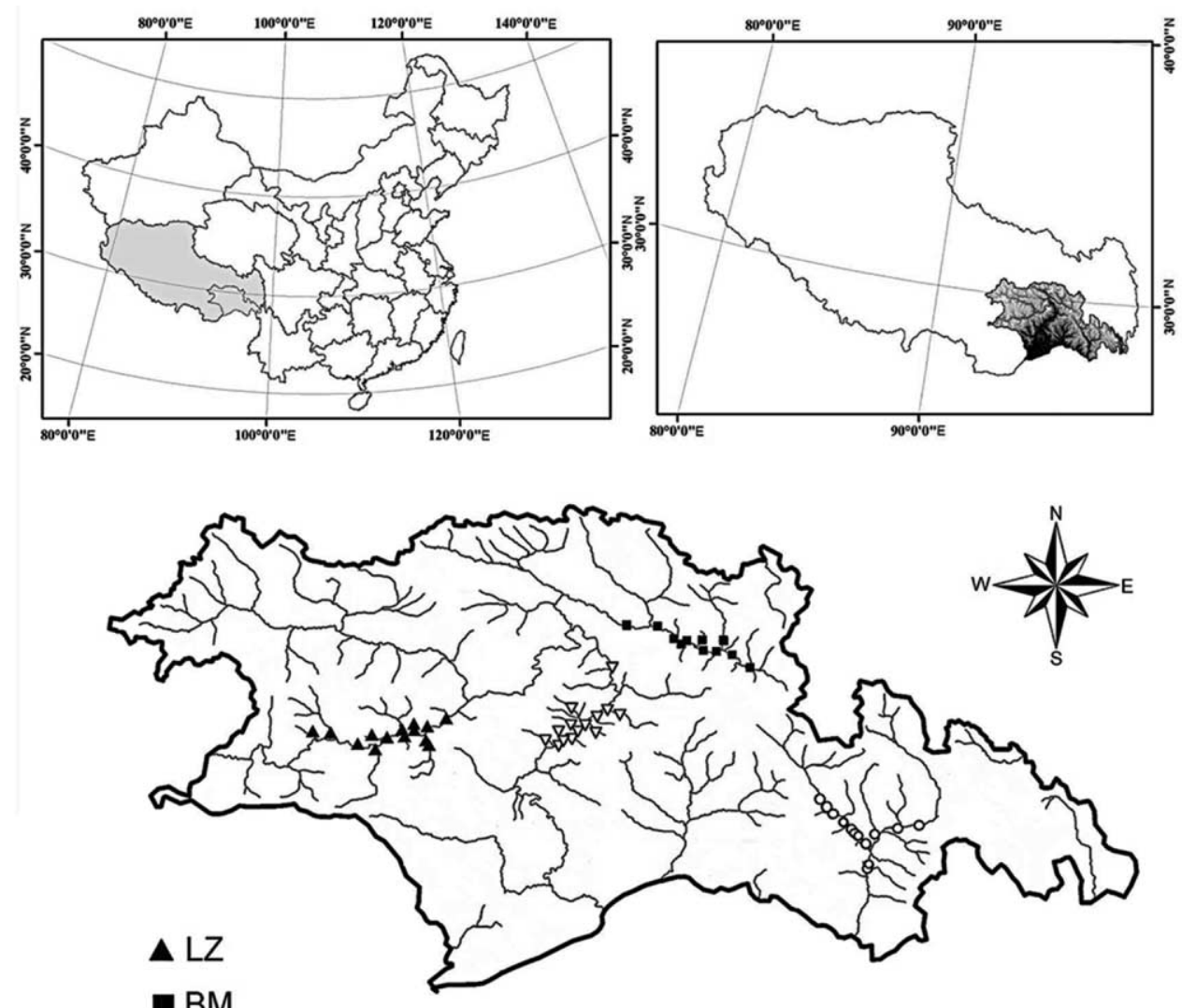

BM

$\mathrm{OCY}$

$\nabla$ MT

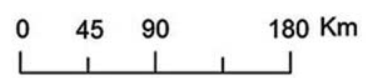

Figure 1. Location of the 52 sampling sites in southeastern Tibet, China. Abbreviations: LZ = Linzhi city; BM = Bomi county; $\mathrm{CY}=$ Chayu county; MT = Motuo county. 
sentative habitats (i.e., riffles or pools) of a $100 \mathrm{~m}$ reach of stream. We took the samples with a Surber sampler $(30-\times$ $30-\mathrm{cm}, 500-\mu \mathrm{m}$ mesh) and used a $500-\mu \mathrm{m}$ mesh to sieve them in the field. We kept the samples in an ice chest until we brought them to the laboratory on the same day. We processed the 3 Surber samples from each site separately by manually sorting the macroinvertebrates from the sediment on a white porcelain plate. We then preserved the specimens with $70 \%$ ethanol. We used a stereomicroscope (Stemi 508; Carl Zeiss Microscopy, Thornwood, New York) to identify most macroinvertebrates, but identified Chironomidae and Oligochaeta by viewing their head capsules with a compound microscope (Imager A2; Carl Zeiss Microscopy). We identified specimens to the lowest operational taxonomic unit (95\% of specimens were identified to genus) based on available references (Brinkhurst 1986, Morse et al. 1994, Wiggins 1996, Dudgeon 1999, Epler 2001). Finally, we combined these 3 replicates prior to analyses to collectively represent the macroinvertebrate assemblage at the site.

We separated the macroinvertebrates into passive and active groups based on their dispersal mode in their adult life stage (Bilton et al. 2001, Van de Meutter et al. 2007, Heino 2013a, b, Heino et al. 2013, Li et al. 2016) (Table S1). This manner of grouping organisms by dispersal mode is common in assemblage-level studies (e.g., Heino 2013b). The passive group included aquatic adults with passive overland dispersal (i.e., Turbellaria, Nematodes, Oligochaeta, Hydrachnidia, and Crustacea) and terrestrial winged adults with passive wind dispersal (i.e., Diptera with small body size such as Ceratopogonidae, Chironomidae, Muscidae, Ephydridae, Simuliidae, and Tanyderidae). In contrast, the active group included terrestrial winged adults with mostly active dispersal (i.e., Odonata, Heteroptera, Hemiptera, Ephemeroptera, Plecoptera, Trichoptera, Megaloptera, and Diptera: Tipulidae).

\section{Environmental and spatial variables}

We measured several environmental variables at each site after we sampled macroinvertebrates. We took these measurements at a consistent time of day at each site. We measured latitude, longitude, and elevation ( $\mathrm{m}$ asl) with portable GPS units (MG721W; UniStrong, Beijing, China). To measure water depth and channel width (GLM80; Bosch, Mt Prospect, Illinois), we averaged values from at least 5 crosschannel transects. We measured current velocity $(\mathrm{m} / \mathrm{s})$ at 5 to 10 random locations along a cross-channel transect with a LJD-10 flowmeter. We used a YSI6680 Multi-probe (Yellow Springs Instruments, Yellow Springs, Ohio) to measure water temperature, $\mathrm{pH}$, and electrical conductivity. We estimated the percentages of substrate particles in 5 size fractions (sand $<2 \mathrm{~mm}$, gravel 2-32 $\mathrm{mm}$, pebble $32-64 \mathrm{~mm}$, cobble 64-256 mm, and boulder $>256 \mathrm{~mm}$ ) in ten $50-\times$ 50 -cm quadrats placed randomly in each sampling site (following Kondolf 1997). Finally, we qualitatively described channel stability at each site based on the Pfankuch Stability Index (Pfankuch 1975).

We developed 2 spatial models that differed in their assumption of the process by which species disperse among sites. The first model created spatial variables based on linear overland (Euclidean) distance between all pairs of sites, which is a simple proxy for overland dispersal. The $2^{\text {nd }}$ model used the watercourse distances among sites when creating spatial variables. This model assumed that movement of species occurred via stream channels. We measured watercourse distances between sites within each region, but not across regions because there is poor hydrologic connectivity across regions.

To create spatial variables for both models based on linear overland distances and watercourse distances, respectively, we conducted spatial modeling according to Borcard and Legendre (2002), using principal coordinates of neighbor matrices (PCNM). We retained the PCNM (based on either the straight-line overland or watercourse distance matrix) coordinates with positive eigenvalues as spatial variables in the subsequent analyses (Gilbert and Bennett 2010). We used the pcnm function in the vegan package (Oksanen et al. 2013) in R ( R Development Core Team. 2016. R: a language and environment for statistical computing. R Foundation for Statistical Computing, Vienna, Austria) to conduct the PCNM analysis. We also constructed a dummy variable 'river basin identity' to indicate largescale spatial differences among river basins (see also Heino et al. 2017b).

\section{Data analysis}

We used 1-way analysis of variance (ANOVA) to test for differences in environmental and biological data (i.e., richness, abundance, and relative abundance of higher taxa within dispersal mode groups) among the 4 regions. We used post hoc tests to make further comparisons. In general, we used Tukey's honestly significant difference (HSD) tests $(e=0.05)$ for these comparisons, but in cases of persistent heteroscedasticity (i.e. when Levene's test was significant) we used Games-Howell tests because they do not assume equal variances between groups. Then, we employed a Venn diagram to visually demonstrate species composition in each region. All ANOVAs were done with the SPSS statistical program (version 22.0, IBM Corp, Chicago, Illinois).

We used canonical analysis of principal coordinates (CAP, Anderson and Robinson 2003) to identify the average differences in community structure and environmental conditions among the 4 regions. $\mathrm{CAP}$ is a variant of principal coordinates analysis (PCOA) that finds the axes that best discriminate among a priori groups in a multivariate cloud of points (Anderson et al. 2008). CAP analysis can be based on any type of resemblance matrix. We used Bray-Curtis similarity matrices for $\log (x+1)$-transformed macroinvertebrate abundance data and Euclidean distance for ap- 
propriately transformed and standardized local habitat data to measure variation among regions. We also tested our CAP results to ensure that the number of PCOA axes we identified best discriminated among regions, and tested whether region centroids differ based on 999 permutations. CAP analyses were run with PERMANOVA + for PRIMER 6.0 (Anderson et al. 2008).

Finally, we conducted separate distance-based redundancy analyses (dbRDA) based on Bray-Curtis dissimilarity for both passive and active dispersers. We analyzed each dispersal mode from the study area as a whole and in each region. This procedure assessed how the focal ecological processes potentially drive variation in assemblage structure (Legendre and Anderson 1999). We used forward selection and Monte Carlo permutations to select the minimum set of environmental and spatial variables that were significantly associated with benthic macroinvertebrate distributions. Prior to the analyses, we checked environmental variables for normality and transformed those violating normality assumptions. We then used variation partitioning (Borcard et al. 1992, Legendre and Legendre 1998) to quantify the relative importance of environmental variables, spatial factors, and river basin identity in explaining assemblage structure variation in the whole study area. We used the same variation partitioning approach to quantify the relative importance of environmental and spatial factors in each of the 4 individual regions.

To determine which spatial model (Euclidean or watercourse distance) was most strongly associated with assemblage structure, we used variation partitioning to analyze both sets of spatial variables. We analyzed each model with both the passive and active dispersal groups and environmental data sets in the 4 individual regions (Gray and Arnott 2011). We used the function varpart in the $\mathrm{R}$ package vegan (Oksanen et al. 2013) to partition the variation for these analyses. We report adjusted fractions of variation from the constrained ordinations because they are unbiased and recommended by previous studies (Peres-Neto et al. 2006). We also used the anova function in the vegan package to test whether the pure fractions of each set of predictor variables were significant based on 999 permutations at a significance level of $\alpha=0.05$.

\section{RESULTS}

\section{Environmental characteristics}

Our measurements revealed broad ranges of elevation (591-3567 m), conductivity $\left(13.1-302.6 \mu \mathrm{S} \mathrm{cm}^{-1}\right)$, dissolved oxygen (6.15-11.51 mg L $\left.{ }^{-1}\right)$, and $\mathrm{pH}(7.14-8.85)$ across the 52 sites in the 4 regions. We detected significant variation among the 4 regions in elevation, water temperature, depth, dissolved oxygen, and $\mathrm{pH}$ (1-way ANOVA, all $p<0.001$; Table S2). The streams in upper canyon regions, especially the glacier-fed ones, had relatively lower water temperature and dissolved oxygen than those in the lower canyon regions, indicating that there were the harsher environment conditions in the high-altitude streams. Moreover, based on the Pfankuch Stability Index, glacier-fed streams in BM had the lowest channel stability, followed by snow-fed streams in $\mathrm{LZ}$ and rain-fed streams in CY and BM (Table S3).

The CAP analysis indicated that environmental characteristics differed distinctly among the 4 regions (Fig. 2A).
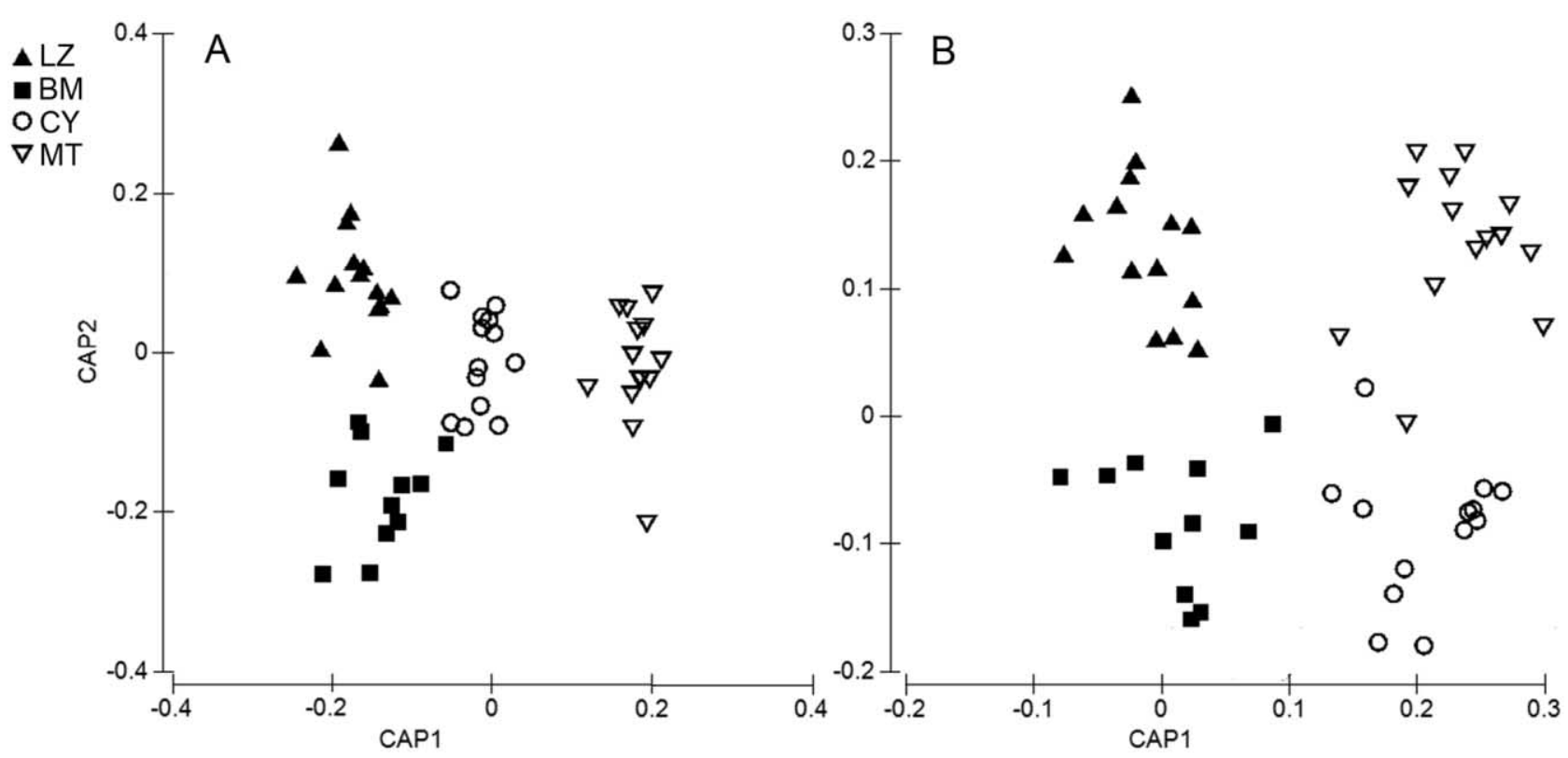

Figure 2. Canonical Analysis of Principal Coordinates (CAP) ordination plots of habitat data (Euclidean distance) (A), and macroinvertebrate abundance data (Bray-Curtis coefficient) (B). 
Further, the percentage of sites classified within their parent group was high $(94.2 \%$, Table 1$)$, confirming the site classification was broadly reliable.

\section{Macroinvertebrate assemblages}

We recorded a total of 195 taxa (90 from LZ, 85 from BM, 94 from CY, 95 from MT) that belonged to 4 phyla, 6 classes, and 69 families. The number of common species (i.e., species shared by at least 2 regions) ranged from 3 to 21 , whereas the number of species unique to each basin was almost the same (23-26; Fig. S1).

Of the 195 taxa we found, we classified 85 taxa as passive dispersers, and the remaining 110 taxa as active dispersers (Table S1). The richness of active dispersers was significantly higher in the upper canyon sites compared with the lower canyon sites $(F=4.798, p=0.005)$, whereas the richness of passive dispersers was not different among these areas $(F=$ 1.037, $p=0.384$ ). Moreover, the relative abundance of some major taxa in each dispersal mode group were significantly different among regions (e.g., passive dispersers: Chironominae $(F=3.484, p=0.022)$, Orthocladiinae $(F=3.623$, $p=0.019)$; active dispersers: Baetidae $(F=7.619, p<0.001)$, Hydropsychidae $(F=15.24, p<0.001)$, and Brachycentridae $(F=2.896, p=0.044)$; Table 2$)$. The CAP analysis showed that assemblage structure differed among the regions (Fig. 2B), with the percentage correct classifications reaching $80.8 \%$ (Table 1).

\section{Environmentally and spatially structured variation in assemblage structure: whole study scale}

For passive dispersers in the whole study area, forward selection based on the dbRDA results identified 5 significant PCNM spatial factors, 3 significant environmental variables (elevation, water depth, and $\mathrm{pH}$ ), and a dummy basin vari- able that were associated with variation in assemblage structure (Fig. 3A). Together, these variables explained $9.7 \%$ of the variation in assemblage structure based on the adjusted $R^{2}$-values. Spatial factors alone explained more of the variance in assemblage structure (2.5\%) than either the environmental variables $(1.7 \%)$ or the dummy basin variable $(1.0 \%)$.

For active dispersers in the whole study area we found that 5 PCNM spatial factors, 6 environmental variables (elevation, \% sand, channel width, dissolved oxygen, $\mathrm{pH}$, and \% cobble), and a dummy basin variable were significantly associated with assemblage structure (Fig. 3B). Together, these variables explained $18.6 \%$ of the variation in community assemblage based on the adjusted $R^{2}$-values. For active dispersers, environmental variables explained $4.6 \%$ of the variation, whereas spatial factors explained $2.8 \%$ and dummy basin variable only explained $0.8 \%$ of the variation.

For both passive and active dispersers, the pure (single) effect of either spatial or environmental variables always explained a significant amount of variation in assemblage structure variation $(p<0.05)$. In contrast, the basin effect alone was never significant (Fig. 3A, B).

\section{Environmentally and spatially structured variation in assemblage structure: single region scale}

The key environmental and spatial factors associated with the assemblage structure of passive and active dispersers varied across the 4 study regions, but for both groups, substrate particle size and large-scale spatial variables emerged as significant correlates in most models (Table 3). For both spatial models (overland or watercourse), pure environmental effects were most strongly associated with passive dispersers in the upper canyon areas (Fig. 4A) and active dispersers in all regions (Table 3, Fig. 4B, D). In contrast, pure spatial effects were most strongly associated with passive dispersers in the lower canyon regions (CY and MT; Fig. 4A, C).More-

Table 1. Summary of the results of Canonical Analysis of Principal Coordinates (CAP) analysis for average differences in habitat variables and macroinvertebrate assemblages among streams. Habitat analysis was based on Euclidean distance on standardized environmental variables and the community analysis on Bray-Curtis dissimilarity on abundance data. Trace $=$ sum of the canonical eigenvalues, delta $=$ the $1^{\text {st }}$ eigenvalue. $p$-values (in parentheses) were based on 999 permutations. $L Z=L$ Linzhi city; $\mathrm{BM}=$ Bomi county; $\mathrm{CY}=$ Chayu county; $\mathrm{MT}=$ Motuo county.

\begin{tabular}{|c|c|c|c|c|c|c|c|c|c|}
\hline & $\mathrm{LZ}$ & $\mathrm{BM}$ & $\mathrm{CY}$ & MT & Total & $\%$ Correct & \% Total correct & Trace $(p)$ & Delta $(p)$ \\
\hline \multicolumn{10}{|c|}{ Habitat } \\
\hline LZ & 13 & 1 & 0 & 0 & 14 & 93 & \multirow{4}{*}{94.2} & \multirow{4}{*}{$1.82(0.0001)$} & \multirow{4}{*}{$0.95(0.0001)$} \\
\hline $\mathrm{BM}$ & 0 & 11 & 0 & 0 & 11 & 100 & & & \\
\hline $\mathrm{CY}$ & 1 & 1 & 11 & 0 & 13 & 85 & & & \\
\hline MT & 0 & 0 & 0 & 14 & 14 & 100 & & & \\
\hline \multicolumn{10}{|c|}{ Assemblages } \\
\hline $\mathrm{LZ}$ & 14 & 0 & 0 & 0 & 14 & 100 & \multirow{4}{*}{80.8} & \multirow{4}{*}{$2.30(0.0001)$} & \multirow{4}{*}{$0.87(0.0001)$} \\
\hline $\mathrm{BM}$ & 0 & 7 & 0 & 4 & 11 & 64 & & & \\
\hline $\mathrm{CY}$ & 0 & 1 & 11 & 1 & 13 & 85 & & & \\
\hline MT & 0 & 1 & 3 & 10 & 14 & 72 & & & \\
\hline
\end{tabular}


Table 2. Mean richness, abundances, and relative abundance of the most common orders, families, or subfamilies of the 2 dispersal groups in the 4 investigated drainage basins. $\mathrm{LZ}=$ Linzhi city; $\mathrm{BM}=$ Bomi county; $\mathrm{CY}=$ Chayu county; $\mathrm{MT}=\mathrm{Motuo}$ county; ind $=$ individual.

\begin{tabular}{|c|c|c|c|c|c|c|}
\hline & $\mathrm{LZ}(n=14)$ & $\mathrm{BM}(n=11)$ & $\mathrm{CY}(n=13)$ & $\operatorname{MT}(n=14)$ & $F$-ratio & $p$ \\
\hline \multicolumn{7}{|l|}{ Richness } \\
\hline Passive & $5.0 \pm 2.4$ & $5.5 \pm 2.3$ & $4.1 \pm 1.8$ & $4.0 \pm 3.5$ & 1.037 & 0.384 \\
\hline Active & $11.2 \pm 3.3^{\mathrm{a}}$ & $11.1 \pm 4.3^{\mathrm{a}}$ & $16.5 \pm 4.2^{\mathrm{b}}$ & $14.5 \pm 5.8^{\mathrm{b}}$ & 4.798 & 0.005 \\
\hline \multicolumn{7}{|l|}{ Abundance (ind $/ \mathrm{m}^{2}$ ) } \\
\hline Passive & $373.5 \pm 334.9$ & $295.9 \pm 242.3$ & $191.5 \pm 283.6$ & $108.9 \pm 48.9$ & 2.72 & 0.054 \\
\hline Active & $797.1 \pm 763.9$ & $850.6 \pm 591.6$ & $837.5 \pm 443.9$ & $1182.1 \pm 884.1$ & 0.911 & 0.442 \\
\hline \multicolumn{7}{|l|}{ Relative abundance (\%) } \\
\hline Passive & $36.0 \pm 26.6^{\mathrm{a}}$ & $28.2 \pm 21.4^{\mathrm{ab}}$ & $16.1 \pm 10.4^{\mathrm{b}}$ & $9.6 \pm 13.5^{\mathrm{b}}$ & 5.455 & 0.002 \\
\hline Chironomidae & $24.9 \pm 24.1^{\mathrm{a}}$ & $27.5 \pm 26.1^{\mathrm{a}}$ & $13.4 \pm 10.2^{\mathrm{b}}$ & $7.6 \pm 13.8^{\mathrm{b}}$ & 3.086 & 0.035 \\
\hline Chironominae & $13.9 \pm 19.6^{\mathrm{a}}$ & $3.5 \pm 6.2^{\mathrm{b}}$ & $1.9 \pm 4.3^{\mathrm{b}}$ & $2.7 \pm 6.4^{\mathrm{b}}$ & 3.484 & 0.022 \\
\hline Orthocladiinae & $7.9 \pm 9.0^{\mathrm{a}}$ & $16.8 \pm 17.7^{\mathrm{b}}$ & $7.8 \pm 8.8^{\mathrm{a}}$ & $3.1 \pm 3.8^{\mathrm{a}}$ & 3.623 & 0.019 \\
\hline Diamesinae & $2.9 \pm 6.1$ & $4.9 \pm 10.4$ & $1.1 \pm 2.8$ & $1.4 \pm 4.7$ & 0.881 & 0.457 \\
\hline Tubificidae & $3.7 \pm 10.1$ & $1.7 \pm 2.4$ & $1.5 \pm 3.1$ & $0.2 \pm 0.6$ & 0.927 & 0.435 \\
\hline Active & $64.0 \pm 26.6^{\mathrm{a}}$ & $71.8 \pm 21.4^{\mathrm{ab}}$ & $83.9 \pm 10.4^{\mathrm{b}}$ & $90.4 \pm 13.5^{\mathrm{b}}$ & 5.455 & 0.002 \\
\hline Ephemeroptera & $29.2 \pm 25.2^{\mathrm{a}}$ & $34.5 \pm 22.8^{\mathrm{a}}$ & $43.0 \pm 25.3^{b}$ & $63.1 \pm 19.6^{\mathrm{b}}$ & 6.723 & 0.01 \\
\hline Baetidae & $17.1 \pm 18.8^{\mathrm{a}}$ & $18.9 \pm 16.3^{\mathrm{a}}$ & $30.7 \pm 13.9^{\mathrm{a}}$ & $47.0 \pm 23.9^{\mathrm{b}}$ & 7.619 & $<0.001$ \\
\hline Ephemerellidae & $4.8 \pm 9.9$ & $3.6 \pm 10.5$ & $5.2 \pm 10.0$ & $2.6 \pm 4.1$ & 0.236 & 0.871 \\
\hline Heptageniidae & $6.7 \pm 13.4$ & $10.6 \pm 15.1$ & $8.2 \pm 8.2$ & $12.3 \pm 10.8$ & 0.623 & 0.603 \\
\hline Trichoptera & $20.5 \pm 18.4$ & $9.4 \pm 8.6$ & $13.7 \pm 10.6$ & $10.5 \pm 10.3$ & 2.141 & 0.106 \\
\hline Rhyacophilidae & $4.7 \pm 5.5$ & $5.9 \pm 5.7$ & $2.6 \pm 1.9$ & $1.7 \pm 1.9$ & 2.775 & 0.051 \\
\hline Brachycentridae & $6.3 \pm 11.9^{\mathrm{a}}$ & $1.8 \pm 4.1^{\mathrm{ab}}$ & $0^{\mathrm{b}}$ & $0^{\mathrm{b}}$ & 2.896 & 0.044 \\
\hline Hydropsychidae & $0.3 \pm 0.7^{\mathrm{a}}$ & $0^{\mathrm{a}}$ & $3.3 \pm 3.5^{\mathrm{a}}$ & $6.6 \pm 7.5^{\mathrm{b}}$ & 7.386 & $<0.001$ \\
\hline Tipulidae & $6.9 \pm 7.3$ & $6.9 \pm 8.3$ & $4.6 \pm 3.7$ & $2.4 \pm 2.5$ & 1.871 & 0.146 \\
\hline
\end{tabular}

over, regardless of the dispersal models we chose, environmental filtering had the most important effect on assemblage structure for both dispersal groups in the glacier-fed region $(\mathrm{BM})$.

\section{DISCUSSION \\ Assemblage structure determinants by dispersal mode: whole study scale}

We found that both deterministic (e.g., environmental filtering) and stochastic (e.g., dispersal) processes were significantly associated with macroinvertebrate assemblage structure across the Yarlung Zangbo Grand Canyon area. However, the relative importance of environmental and spatial processes on assemblage structure depended on dispersal mode. Generally, spatial processes were more important in regulating variation of the assemblage structure of passive dispersers compared to environmental filtering that showed a greater importance for active dispersers (Fig. 3). Such findings are in accordance with several previous studies on the interaction between dispersal mode and the processes that structure aquatic communities (Heino 2013a, Padial et al. 2014, Cauvy-Fraunié et al. 2015, Göthe et al.
2017, Hill et al. 2017). However, we found no effect of river basin identity for either passive or active dispersers, which was in contrast to findings in boreal lowland macroinvertebrate assemblages (Heino et al. 2017a). As the shared effects of basin identity and environmental and/or spatial factors in our models are relatively high (from $0.3-4.4 \%$ ), this result should arise because basin identity influences macroinvertebrate distributions indirectly by interacting with other sets of variables. Alternatively, this difference could be a result of our use of genus-level taxonomic resolution, when species-level resolution may be necessary to detect significant basin effects among study regions.

The adults of active dispersers (e.g., mayflies, caddisflies, stoneflies, and dragonflies) in stream macroinvertebrate assemblages have robust wings and possess generally strong overland dispersal capacity. These species can therefore select suitable habitats actively and efficiently, and usually show stronger environmental control and weaker effects of spatial structuring (Heino 2013a, Padial et al. 2014, Hill et al. 2017). In addition, the main active dispersers in our study, such as mayfly, stonefly and caddisfly taxa, are sensitive to environmental variation in highland streams, and their distribution may largely depend on environmental fea- 
A

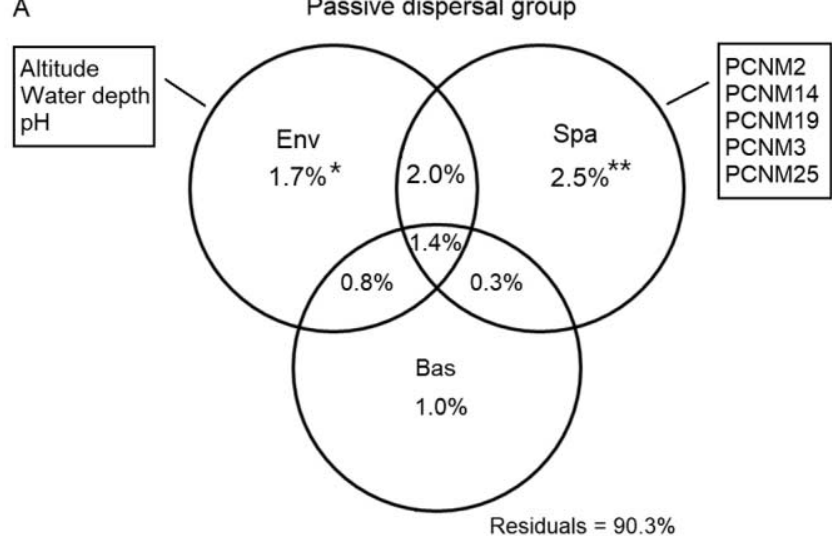

B

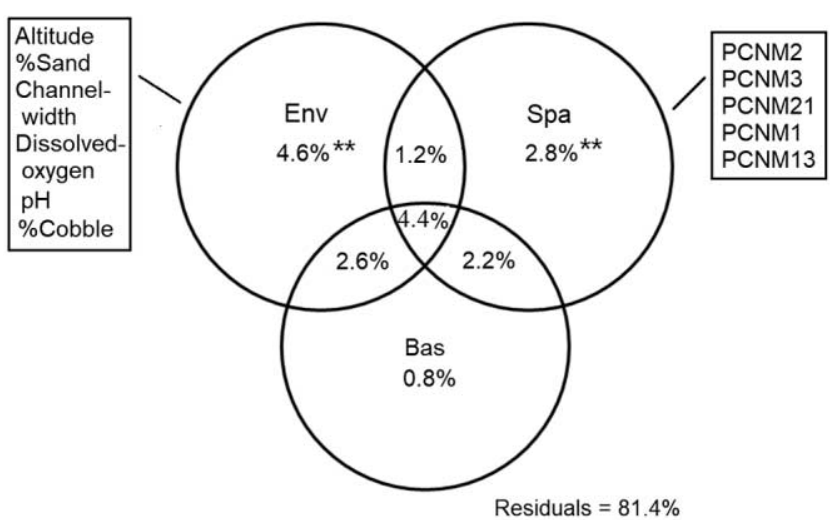

Figure 3. Venn diagrams showing the association between environmental variables (Env), spatial factors (Spa), and dummy basin variables (Bas) and assemblage structures of passive (A) and active (B) dispersal groups in the whole study area. Values represent adjusted $R^{2}$-values. ${ }^{* *}=p<0.01,{ }^{*}=p<0.05$.

tures (Jacobsen 2008, Madsen et al. 2015). In contrast, passive dispersers consist primarily of aquatic worms and midges that are primarily dispersed by passive water flows and wind, respectively (Li et al. 2016). These species do not actively disperse overland and probably have difficulty colonizing more distant sites, which can result in their absence from those sites even if they are environmentally suitable (Thompson et al. 1999, Lester et al. 2007). Additionally, some passive dispersers (e.g., aquatic worms and midges) that are ecologically tolerant, can survive and reproduce in some harsh conditions, showing insensitivity to environmental variation in alpine streams (Milner et al. 2001, Chaves et al. 2008, Madsen et al. 2015).

\section{Assemblage structure determinants by dispersal mode: single region scale}

Our study spanned drainage basins with large variation in elevation and highly heterogeneous environmental conditions. The variation partitioning analysis showed that the relative influence of environmental and spatial processes on assemblage structures of passive and active dispersers in individual regions were similar to the results for the study region as a whole (Table 3, Fig. 4A-D). This result was consistent regardless of the spatial model (overland or watercourse) used, supporting previous perspective that spatial eigenvectors based on either overland or watercourse distances between sites provide similar information about spatial effects on community structures (Grönroos et al. 2013, CauvyFraunié et al. 2015).

Our study also implies that the environmental filtering effects were more important than spatial effects in regions with harsh habitats, i.e., the upper canyon regions. In high altitudes, factors associated with elevation were probably the key factors that determined invertebrate assemblage structure, because the high climatic and environmental variation that occurs along steep elevational gradients can induce strong environmental filtering effects on biota (Willis et al. 2010, Sundqvist et al. 2013). Additionally, other environmental factors that significantly change along elevation gradients can also limit the survival, growth, fecundity, and other vital activities of organisms in alpine streams. For example, the low water temperature and dissolved oxygen levels in highland streams often govern the physiology and distribution patterns of macroinvertebrates (Jacobsen 2008, Madsen et al. 2015). Thus, the harsh habitat conditions in high-elevation streams probably serve as a strong filter for species distributions, and lead to the dominance of environmental filtering in the upper canyon.

Furthermore, dispersal limitation has a strong influence in species-rich communities that harbor large numbers of rare species (Hubbell 2001, Qian and Ricklefs 2007, Myers et al. 2013). The distribution of rare species may depend more on dispersal from nearby habitats compared with common species, because rare species may experience local extinction more frequently than common species (Tsang and Bonebrake 2017). Based on the same number of samples, the lower canyons (CY and MT) that have subtropical climates had more rare species ( $\sim 54$ and $71 \%$ singleton species in CY and MT, respectively), whereas the upper canyon areas that have temperate climates had fewer rare species ( $~ 33$ and 44\% singleton species in LZ and BM, respectively). Thus, the effects of spatial processes relative to environmental filtering may have increased from the upper to lower canyon because of the change in numbers of rare species.

Surprisingly, we did not detect any effect of spatial structuring in glacier-fed stream macroinvertebrate assemblages (BM region), even for the passive dispersers. This lack of association is probably a result of the exceptionally harsh hydrological features in glacier-fed streams as well as the highelevation environmental conditions filtering a large number of the species that reach these sites. Glacial cover in catchments has a negative effect on both species richness and abundance of macroinvertebrates (Maiolini and Lencioni 2001, Milner et al. 2001, Laursen et al. 2015). These harsh 
Table 3. Results of distanced-based redundancy analyses (dbRDA) and variance partitioning, showing the relative influence of significant environmental and spatial variables on the assemblage structure of the 2 dispersal mode groups within each of the 4 individual regions. Values for each explained fraction are adjusted $R^{2}$. Fractions are [E] pure environmental, [E $\times \mathrm{S}$ ] shared, and $[\mathrm{S}]$ pure spatial. LZ = Linzhi city; BM = Bomi county; CY = Chayu county; MT = Motuo county.

\begin{tabular}{|c|c|c|c|c|c|c|c|}
\hline & Data & Distance & Spatial variables & Environmental variables & {$[E]$} & $\begin{array}{c}\text { Fractions } \\
{[E \times S]}\end{array}$ & {$[S]$} \\
\hline \multirow[t]{4}{*}{ LZ } & \multirow[t]{2}{*}{ Passive } & Overland & PCNM1 & \multirow{2}{*}{ Altitude, $\mathrm{pH}, \%$ sand } & 0.198 & 0.007 & 0.041 \\
\hline & & Watercourse & PCNM1 & & 0.202 & 0.003 & 0.028 \\
\hline & \multirow[t]{2}{*}{ Active } & Overland & - & \multirow{2}{*}{$\%$ Sand, altitude, water temperature } & 0.136 & - & - \\
\hline & & Watercourse & - & & 0.136 & - & - \\
\hline \multirow[t]{4}{*}{$\mathrm{BM}$} & \multirow[t]{2}{*}{ Passive } & Overland & - & \multirow{2}{*}{ Channel width, Dissolved oxygen } & 0.204 & - & - \\
\hline & & Watercourse & - & & 0.204 & - & - \\
\hline & \multirow[t]{2}{*}{ Active } & Overland & - & \multirow{2}{*}{ Dissolved oxygen, Water depth } & 0.236 & - & - \\
\hline & & Watercourse & - & & 0.236 & - & - \\
\hline \multirow[t]{4}{*}{$\mathrm{CY}$} & \multirow[t]{2}{*}{ Passive } & Overland & PCNM1,2 & \multirow{2}{*}{$\%$ Boulder } & $0.001^{\mathrm{ns}}$ & 0.066 & 0.089 \\
\hline & & Watercourse & PCNM1,2,3,9 & & 0.025 & 0.042 & 0.227 \\
\hline & \multirow[t]{2}{*}{ Active } & Overland & PCNM2 & \multirow{2}{*}{ Channel width, $\mathrm{pH}$} & 0.166 & 0.048 & $0.004^{\mathrm{ns}}$ \\
\hline & & Watercourse & - & & 0.214 & - & - \\
\hline \multirow[t]{4}{*}{ MT } & \multirow[t]{2}{*}{ Passive } & Overland & PCNM3 & \multirow{4}{*}{$\begin{array}{l}\% \text { Gravel } \\
\text { Water temperature, \% Gravel }\end{array}$} & 0.013 & 0.021 & 0.028 \\
\hline & & Watercourse & PCNM3 & & 0.020 & 0.014 & 0.042 \\
\hline & \multirow[t]{2}{*}{ Active } & Overland & PCNM2 & & 0.062 & 0.052 & 0.010 \\
\hline & & Watercourse & - & & 0.113 & - & - \\
\hline
\end{tabular}

${ }^{\mathrm{ns}}$ Non-significant fraction $(p>0.05)$; all other testable fractions were significant at $p<0.05$.
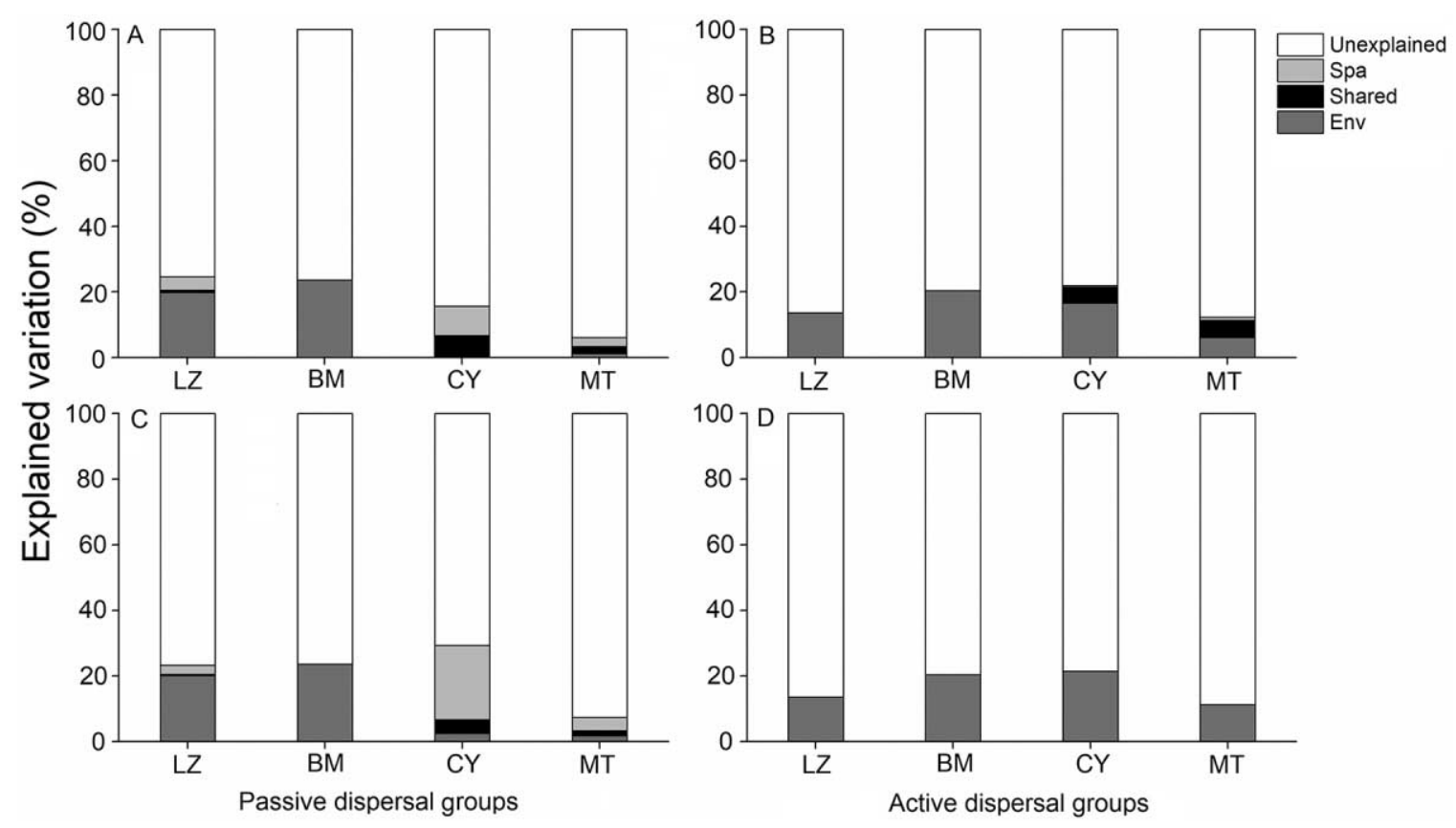

Figure 4. Percentage of variation in the assemblage structure in each region associated with (explained by) environmental variables (Env), spatial factors (Spa), and interaction effects (Shared). Percent of variance that is also included. Separate analyses were conducted for both passive and active dispersers, for overland-based spatial factors (A, B), and watercourse-based spatial factors (C, D). 
conditions are caused by the cold water and unstable channel conditions (Brittain and Milner 2001, Maiolini and Lencioni 2001), ultraoligotrophic conditions (Brittain and Milner 2001, Laursen et al. 2015), and high loads of suspended fine inorganic sediment (Holte and Gulliksen 1998). These conditions may lead to specialist assemblages of tolerant, pioneer taxa in glacial streams. Therefore, the relationship between invertebrate communities and spatial processes may be obscured by the strong environmental filtering process, leading to an absolute predominance of environmental effects in the BM region.

\section{Caveats}

The robustness of our conclusions depends on whether a meaningful distinction exists between the taxa that we designated as active or passive dispersers. Ideally, we would have used species- or genus-level information on dispersal traits or modes instead of the coarse dispersal groupings we used. Unfortunately, this information is unavailable for macroinvertebrates in most regions, and the type of coarse grouping we used is common in community-level research (e.g., Van de Meutter et al. 2007, Heino 2013a, b).

Another limitation in our study is that we used a limited number of local habitat variables (e.g., dissolved oxygen, temperature, $\mathrm{pH}$, and conductivity). We did not collect some potentially important variables, such as riparian vegetation cover (Death and Collier 2010), catchment land-use types (Monaghan et al. 2000), and wind dynamics (Bertin et al. 2015), and other parameters. Lack of these variables could account for the relatively low variation ( $10-20 \%)$ of assemblage structure explained by our overall dbRDA models. However, many similar studies across the world have reported low levels of explained variation as observed here (Heino et al. 2015a).

An additional problem could be that a snapshot sample of stream macroinvertebrate assemblages might not accurately quantify the strongest relationships between assemblage structure and ecological factors, because these relationships are likely to change over time (Padial et al. 2014, Jiang et al. 2017). In other words, the importance of variables structuring assemblage composition may change at monthly and yearly temporal scales. Seasonal and inter-annual surveys of macroinvertebrate assemblages in many geographic regions may be necessary to assess the generality of our findings.

\section{Conclusions}

Our results support the hypothesis that dispersal mode affects the relative importance of deterministic (i.e., environmental filtering) and stochastic (i.e., dispersal) processes in structuring stream macroinvertebrate assemblages. We concluded that assemblages of passive dispersers are affected more by spatial processes than environmental conditions, whereas assemblages of active dispersers are deter- mined mainly by environmental filtering. Moreover, we found that environmental filters were most important in determining macroinvertebrate assemblage structure at high altitudes, especially in glacier-fed streams. This finding highlighted the importance of species sorting processes in harsh environmental conditions. In general, our study provides information about the coexistence of stream organisms in the Yarlung Zangbo Grand Canyon area across different altitude ranges and highlights the significance of linking dispersal traits and multiple ecological factors underlying metacommunity organization.

\section{ACKNOWLEDGEMENTS}

Author contributions: ZL, XJ, and ZX conceived the study. ZL, JW, and XM collected specimens. ZL identified specimens. ZL, JW, XM, MS, and XJ analyzed data. MS made maps. ZL wrote the manuscript with input, guidance, and help from $\mathrm{JH}, \mathrm{XJ}$, and ZX.

The authors are greatly indebted to Dr. Liang Cao, Pengcheng Lin, and Mingzheng Li for their valuable help during the field surveys of this study. This work was supported by the National Natural Science Foundation of China (No. 31400469, 41571495), the National Science and Technology Basic Research Program (No. 2015FY110400-4), Special Foundation for Biodiversity Conservation of China's Ministry of Environmental Protection and Powerchina Chengdu Engineering Corporation Limited.

\section{LITERATURE CITED}

Anderson, M. J., R. N. Gorley, and R. K. Clarke. 2008. PERMANOVA + for PRIMER: guide to software and statistical methods. PRIMER-E, Plymouth, UK.

Anderson, M. J., and J. Robinson. 2003. Generalized discriminant analysis based on distances. Australian and New Zealand Journal of Statistics 45:301-318.

Bertin, A., E. Alvarez, N. Gouin, E. Gianoli, S. Montecinos, S. Lek, S. Gascoin, and S. Lhermitte. 2015. Effects of wind-driven spatial structure and environmental heterogeneity on highaltitude wetland macroinvertebrate assemblages with contrasting dispersal modes. Freshwater Biology 60:297-310.

Bilton, D. T., J. R. Freeland, and B. Okamura. 2001. Dispersal in freshwater invertebrates. Annual Review of Ecology and Systematics 32:159-181.

Borcard, D., and P. Legendre. 2002. All-scale spatial analysis of ecological data by means of principal coordinates of neighbour matrices. Ecological Modelling 153:51-68.

Borcard, D., P. Legendre, and P. Drapeau. 1992. Partialling out the spatial component of ecological variation. Ecology 73:10451055.

Brinkhurst, R. O. 1986. Guide to the freshwater aquatic microdrile oligochaetes of North America. Canadian Special Publication of Fisheries and Aquatic Sciences. Volume 84. Department of Fisheries and Oceans, Ottawa, Ontario.

Brittain, J. E., and A. M. Milner. 2001. Ecology of glacier-fed rivers: current status and concepts. Freshwater Biology 46:15711578 .

Cauvy-Fraunié, S., R. Espinosa, P. Andino, D. Jacobsen, and O. Dangles. 2015. Invertebrate metacommunity structure and dy- 
namics in an Andean glacial stream network facing climate change. PloS ONE 10:e136793.

Chaves, M. L., M. Rieradevall, P. Chainho, J. L. Costa, M. J. Costa, and N. Prat. 2008. Macroinvertebrate communities of nonglacial high altitude intermittent streams. Freshwater Biology 53:55-76.

Cottenie, K. 2005. Integrating environmental and spatial processes in ecological community dynamics. Ecology Letters 8:11751182.

Dawaciren, B., Q. Baima. 2008. Analysis of hydrological characteristics in Niyang river basin. Journal of China Hydrology 28:92-94 (in Chinese).

Death, R. G., and K. J. Collier. 2010. Measuring stream macroinvertebrate responses to gradients of vegetation cover: when is enough enough? Freshwater Biology 55:1447-1464.

Deng, L., D. Chen, and L. Deng. 2011. Ecological evaluation of Yarlung Zangbo Grand Canyon National Nature Reserve in Tibet. Scientia Silvae Sinicae 47:1-6.

Dudgeon, D. 1999. Tropical Asian streams: zoobenthos, ecology and conservation. Hong Kong University Press, Aberdeen, Hong Kong.

Epler, J. H. 2001. Identification manual for the larval Chironomidae (Diptera) of North and South Carolina. A guide to the taxonomy of the midges of the southeastern United States, including Florida. Special Publication SJ2001-SP13. North Carolina Department of Environment and Natural Resources, Raleigh, North Carolina, and St Johns River Water Management District, Palatka, Florida.

Gilbert, B., and J. R. Bennett. 2010. Partitioning variation in ecological communities: do the numbers add up? Journal of Applied Ecology 47:1071-1082.

Göthe, E., A. Baattrup-Pedersen, P. Wiberg-Larsen, D. Graeber, E. A. Kristensen, and N. Friberg. 2017. Environmental and spatial controls of taxonomic versus trait composition of stream biota. Freshwater Biology 62:397-413.

Gray, D. K., and S. E. Arnott. 2011. Does dispersal limitation impact the recovery of zooplankton communities damaged by a regional stressor? Ecological Applications 21:1241-1256.

Grimaldo, J. T., L. M. Bini, V. L. Landeiro, M. T. O'Hare, J. Caffrey, A. Spink, S. V. Martins, M. P. Kennedy, and K. J. Murphy. 2016. Spatial and environmental drivers of macrophyte diversity and community composition in temperate and tropical calcareous rivers. Aquatic Botany 132:49-61.

Grönroos, M., J. Heino, T. Siqueira, V. L. Landeiro, J. Kotanen, and L. M. Bini. 2013. Metacommunity structuring in stream networks: roles of dispersal mode, distance type, and regional environmental context. Ecology and Evolution 3:4473-4487.

Heino, J. 2013a. Does dispersal ability affect the relative importance of environmental control and spatial structuring of littoral macroinvertebrate communities? Oecologia 171:971980.

Heino, J. 2013b. Environmental heterogeneity, dispersal mode, and co-occurrence in stream macroinvertebrates. Ecology and Evolution 3:344-355.

Heino, J., J. Alahuhta, T. Ala-Hulkko, H. Antikainen, L. M. Bini, N. Bonada, T. Datry, T. Erős, J. Hjort, O. Kotavaara, A. S. Melo, and J. Soininen. 2017a. Integrating dispersal proxies in ecological and environmental research in the freshwater realm. Environmental Reviews 25: 334-349.
Heino, J., M. Grönroos, J. Ilmonen, T. Karhu, M. Niva, and L. Paasivirta. 2013. Environmental heterogeneity and $\beta$ diversity of stream macroinvertebrate communities at intermediate spatial scales. Freshwater Science 32:142-154.

Heino, J., M. Grönroos, J. Soininen, R. Virtanen, and T. Muotka. 2012. Context dependency and metacommunity structuring in boreal headwater streams. Oikos 121:537-544.

Heino, J., A. S. Melo, L. M. Bini, F. Altermatt, S. A. Al-Shami, D. G. Angeler, N. Bonada, C. Brand, M. Callisto, and K. Cottenie, O. Dangles, D. Dudgeon, A. Encalada, E. Göthe, M. Grönroos, N. Hamada, D. Jacobsen, V. L. Landeiro, R. Ligeiro, R. T. Martins, M. L. Miserendino, C. S. M. Rawi, M. E. Rodrigues, F. de O. Roque, L. Sandin, D. Schmera, L. F. Sgarbi, J. P. Simaika, T. Siqueira, R. M. Thompson, and C. R. Townsend. 2015a. A comparative analysis reveals weak relationships between ecological factors and beta diversity of stream insect metacommunities at two spatial levels. Ecology and Evolution 5:1235-1248.

Heino, J., A. S. Melo, T. Siqueira, J. Soininen, S. Valanko, and L. M. Bini. 2015b. Metacommunity organisation, spatial extent and dispersal in aquatic systems: patterns, processes and prospects. Freshwater Biology 60:845-869.

Heino, J., J. Soininen, J. Alahuhta, J. Lappalainen, and R. Virtanen. 2017b. Metacommunity ecology meets biogeography: effects of geographical region, spatial dynamics and environmental filtering on community structure in aquatic organisms. Oecologia 183:121-137.

Heino, J., J. Soininen, J. Lappalainen, and R. Virtanen. 2005. The relationship between species richness and taxonomic distinctness in freshwater organisms. Limnology and Oceanography 50:978-986.

Hill, M. J., J. Heino, I. Thornhill, D. B. Ryves, and P. J. Wood. 2017. Effects of dispersal mode on the environmental and spatial correlates of nestedness and species turnover in pond communities. Oikos 126:1575-1585.

Hirzel, A. H., and G. Le Lay. 2008. Habitat suitability modelling and niche theory. Journal of Applied Ecology 45:1372-1381.

Holte, B., and B. Gulliksen. 1998. Common macrofaunal dominant species in the sediments of some north Norwegian and Svalbard glacial fjords. Polar Biology 19:375-382.

Hubbell, S. P. 2001. The unified neutral theory of biodiversity and biogeography. Monographs in population biology. Volume 32. Princeton University Press, Princeton, New Jersey.

Jacobsen, D. 2008. Low oxygen pressure as a driving factor for the altitudinal decline in taxon richness of stream macroinvertebrates. Oecologia 154:795-807.

Jiang, X., Z. Xie, and Y. Chen. 2013. Longitudinal patterns of macroinvertebrate communities in relation to environmental factors in a Tibetan-Plateau river system. Quaternary International 304:107-114.

Jiang, X., J. Xiong, and Z. Xie. 2017. Longitudinal and seasonal patterns of macroinvertebrate communities in a large undammed river system in Southwest China. Quaternary International 440:1-12.

Kondolf, G. M. 1997. Application of the pebble count notes on purpose, method, and variants. Journal of the American Water Resources Association 33:79-87.

Landeiro, V. L., L. M. Bini, A. S. Melo, A. M. O. Pes, and W. E. Magnusson. 2012. The roles of dispersal limitation and envi- 
ronmental conditions in controlling caddisfly (Trichoptera) assemblages. Freshwater Biology 57:1554-1564.

Laursen, S. K., L. Hamerlik, K. Moltesen, K. S. Christoffersen, and D. Jacobsen. 2015. Diversity and composition of macroinvertebrate assemblages in high-altitude Tibetan streams. Inland Waters 5:263-274.

Legendre, P., and M. J. Anderson. 1999. Distance-based redundancy analysis: testing multispecies responses in multifactorial ecological experiments. Ecological Monographs 69:1-24.

Legendre, P., and L. Legendre. 1998. Numerical Ecology. $2^{\text {nd }}$ edition. Elsevier, Amsterdam, The Netherlands.

Leibold, M. A., and J. M. Chase. 2017. Metacommunity ecology. Princeton University Press, Princeton, New Jersey.

Leibold, M. A., M. Holyoak, N. Mouquet, P. Amarasekare, J. M. Chase, M. F. Hoopes, R. D. Holt, J. B. Shurin, R. Law, D. Tilman, M. Loreau, and A. Gonzalez. 2004. The metacommunity concept: a framework for multi-scale community ecology. Ecology Letters 7:601-613.

Lester, S. E., B. I. Ruttenberg, S. D. Gaines, and B. P. Kinlan. 2007. The relationship between dispersal ability and geographic range size. Ecology Letters 10:745-758.

Li, F., A. Sundermann, S. Stoll, and P. Haase. 2016. A newly developed dispersal metric indicates the succession of benthic invertebrates in restored rivers. Science of the Total Environment 569-570:1570-1578.

Li, F., Z. Xu, W. Liu, and Y. Zhang. 2014. The impact of climate change on runoff in the Yarlung Tsangpo River basin in the Tibetan Plateau. Stochastic Environmental Research and Risk Assessment 28:517-526.

Logue, J. B., N. Mouquet, H. Peter, H. Hillebrand, and Metacommunity Working Group. 2011. Empirical approaches to metacommunities: a review and comparison with theory. Trends in Ecology and Evolution 26:482-491.

Madsen, P. B., A. Morabowen, P. Andino, R. Espinosa, S. CauvyFraunié, O. Dangles, and D. Jacobsen. 2015. Altitudinal distribution limits of aquatic macroinvertebrates: an experimental test in a tropical alpine stream. Ecological Entomology 40:629638.

Maiolini, B., and V. Lencioni. 2001. Longitudinal distribution of macroinvertebrate assemblages in a glacially influenced stream system in the Italian Alps. Freshwater Biology 46:16251639.

Martiny, J. B. H., B. J. Bohannan, J. H. Brown, R. K. Colwell, J. A. Fuhrman, J. L. Green, M. C. Horner-Devine, M. Kane, J. A. Krumins, C. R. Kuske, P. J. Morin, S. Naeem, L. Øvreås, A.-L. Reysenbach, V. H. Smith, and J. T. Staley. 2006. Microbial biogeography: putting microorganisms on the map. Nature Reviews Microbiology 4:102-112.

Milner, A. M., J. E. Brittain, E. Castella, and G. E. Petts. 2001. Trends of macroinvertebrate community structure in glacierfed rivers in relation to environmental conditions: a synthesis. Freshwater Biology 46:1833-1847.

Monaghan, K. A., M. R. Peck, P. A. Brewin, M. Masiero, E. Zarate, P. Turcotte, and S. J. Ormerod. 2000. Macroinvertebrate distribution in Ecuadorian hill streams: the effects of altitude and land use. Archiv für Hydrobiologie 149:421-440.

Morse, J. C., L. Yang, and L. Tian. 1994. Aquatic insects of China useful for monitoring water quality. Hohai University Press, Nanjing, China.
Myers, J. A., J. M. Chase, I. Jiménez, P. M. Jørgensen, A. AraujoMurakami, N. Paniagua-Zambrana, and R. Seidel. 2013. Betadiversity in temperate and tropical forests reflects dissimilar mechanisms of community assembly. Ecology Letters 16:151157.

Oksanen, J., F. G. Blanchet, R. Kindt, P. Legendre, P. R. Minchin, R. B. O'Hara, G. L. Simpson, P. Solymos, M. H. H. Stevens, and H. Wagner. 2013. vegan: community ecology package. R package version 2.0-10. R Project for Statistical Computing, Vienna, Austria.

Padial, A. A., F. Ceschin, S. A. J. Declerck, L. De Meester, C. C. Bonecker, F. A. Lansac-Tôha, L. Rodrigues, L. C. Rodrigues, S. Train, L. F. M. Velho, and L. M. Bini. 2014. Dispersal ability determines the role of environmental, spatial and temporal drivers of metacommunity structure. PLoS ONE 9:e111227.

Patrick, C. J., M. J. Cooper, and D. G. Uzarski. 2014. Dispersal mode and ability affect the spatial turnover of a wetland macroinvertebrate metacommunity. Wetlands 34:11331143.

Peres-Neto, P. R., P. Legendre, S. Dray, and D. Borcard. 2006. Variation partitioning of species data matrices: estimation and comparison of fractions. Ecology 87:2614-2625.

Pfankuch, D. J. 1975. Stream reach inventory and channel stability evaluation. United States Department of Agriculture Forest Service, Region 1, Missoula, Montana, USA.

Qian, H., C. Badgley, and D. L. Fox. 2009. The latitudinal gradient of beta diversity in relation to climate and topography for mammals in North America. Global Ecology and Biogeography 18:111-122.

Qian, H., and R. E. Ricklefs. 2007. A latitudinal gradient in largescale beta diversity for vascular plants in North America. Ecology Letters 10:737-744.

Sundqvist, M. K., N. J. Sanders, and D. A. Wardle. 2013. Community and ecosystem responses to elevational gradients: processes, mechanisms, and insights for global change. Annual Review of Ecology, Evolution, and Systematics 44:261-280.

Thompson, K., K. J. Gaston, and S. R. Band. 1999. Range size, dispersal and niche breadth in the herbaceous flora of central England. Journal of Ecology 87:150-155.

Thompson, R., and C. Townsend. 2006. A truce with neutral theory: local deterministic factors, species traits and dispersal limitation together determine patterns of diversity in stream invertebrates. Journal of Animal Ecology 75:476-484.

Tonkin, J. D., F. Altermatt, D. S. Finn, J. Heino, J. D. Olden, S. U. Pauls, and D. Lytle. 2018. The role of dispersal in river network metacommunities: patterns, processes, and pathways. Freshwater Biology 63:141-163.

Tonkin, J. D., J. Heino, A. Sundermann, P. Haase, and S. C. Jähnig. 2016a. Context dependency in biodiversity patterns of central German stream metacommunities. Freshwater Biology 61:607620.

Tonkin, J. D., R. D. Tachamo Shah, D. N. Shah, F. Hoppeler, S. C. Jähnig, and S. U. Pauls. 2016b. Metacommunity structuring in Himalayan streams over large elevational gradients: the role of dispersal routes and niche characteristics. Journal of Biogeography 44:62-74.

Tsang, T. P. N., and T. C. Bonebrake. 2017. Contrasting roles of environmental and spatial processes for common and rare urban butterfly species compositions. Landscape Ecology 32:47-57. 
Urban, M. C. 2004. Disturbance heterogeneity determines freshwater metacommunity structure. Ecology 85:2971-2978.

Van de Meutter, F., L. De Meester, and R. Stoks. 2007. Metacommunity structure of pond macroinvertebrates: effects of dispersal mode and generation time. Ecology 88:1687-1695.

Wiggins, G. B. 1996. Larvae of the North American caddisfly genera (Trichoptera). University of Toronto Press, Toronto, Ontario.

Willis, C. G., M. Halina, C. Lehman, P. B. Reich, A. Keen, S. McCarthy, and J. Cavender-Bares. 2010. Phylogenetic community structure in Minnesota oak savanna is influenced by spatial extent and environmental variation. Ecography 33:565-577.

Wright, J. S. 2002. Plant diversity in tropical forests: a review of mechanisms of species coexistence. Oecologia 130:1-14.

Xiang, L. Z., Z. H. Liu, J.-B. Liu, L. Lin, X. Zou, M.-Y. Lou, R. Dai, and Y. Zhu. 2013. Variation of glaciers and its response to cli- mate change in Bomi County of Tibet Autonomous Region in 1980-2010. Journal of Glaciology and Geocryology 35:593600.

Yao, T., J. Pu, A. Lu, Y. Wang, and W. Yu. 2007. Recent glacial retreat and its impact on hydrological processes on the Tibetan Plateau, China, and surrounding regions. Arctic, Antarctic, and Alpine Research 39:642-650.

Zhang, M., Q. Ren, X. Wei, J. Wang, X. Yang, and Z. Jiang. 2011. Climate change, glacier melting and streamflow in the Niyang River Basin, Southeast Tibet, China. Ecohydrology 4:288298.

Zhao, K., K. Song, Y. Pan, L. Wang, L. Da, and Q. Wang. 2017. Metacommunity structure of zooplankton in river networks: roles of environmental and spatial factors. Ecological Indicators 73:96-104. 